\title{
Primary Ewing's Sarcoma of the Sinonasal Tract: A Case Report
}

\author{
Tomoharu Suzuki $^{\text {a }}$ Ryuji Yasumatsu ${ }^{a}$ Torahiko Nakashima ${ }^{a}$ \\ Shuji Arita ${ }^{b}$ Hidetaka Yamamoto $^{c}$ Takashi Nakagawa $^{a}$ \\ aDepartment of Otorhinolaryngology, Graduate School of Medical Sciences, Kyushu \\ University, Fukuoka, Japan; ${ }^{b}$ Department of Medicine and Biosystemic Science, Graduate \\ School of Medical Sciences, Kyushu University, Fukuoka, Japan; ' Department of Anatomic \\ Pathology, Graduate School of Medical Sciences, Kyushu University, Fukuoka, Japan
}

\section{Keywords}

Ewing's sarcoma $\cdot$ Sinonasal tract $\cdot$ VDC-IE $\cdot$ Chemotherapy $\cdot$ Radiation therapy

\begin{abstract}
A 23-year-old male presented with a 3-month history of left purulent rhinorrhea, progressive nasal obstruction, and intermittent epistaxis. A fiberoptic examination revealed a large vascular polypoid mass completely filling the left nasal cavity. CT and MRI scans showed a large hypervascular mass involving the left nasal airway, maxillary antrum, and the anterior ethmoid cells. There was no bony erosion or contiguous spread, and the remaining sinuses, orbit, and cranial fossa were uninvolved. The patient underwent complete removal of the mass via an external lateral rhinotomy approach. The soft mass was large and vascular. A microscopic analysis revealed an undifferentiated tumor consisting of a solid sheet of small, round blue cells. Mitotic figures were also present. Immunohistochemically, the tumor cells were strongly positive for CD99. Molecular studies using a PCR confirmed the chromosomal translocation of FLI1 (exon 6). These findings were considered diagnostic for Ewing's sarcoma. Postoperatively, the patient was treated with combined chemotherapy and radiotherapy. Adjuvant chemotherapy consisting of vincristine, doxorubicin, and cyclophosphamide alternating with ifosfamide and etoposide (total: 7 cycles) was commenced. He also received radiation therapy for local control (total dose: $50.4 \mathrm{~Gy}$ ). The patient is currently alive without any evidence of recurrence or metastasis.

(C) 2017 The Author(s)

Published by S. Karger AG, Basel
\end{abstract}




\section{Introduction}

Ewing's sarcoma (EWS) is a highly malignant, small, round cell tumor that originated from the primitive neuroectodermal cells, as first described by James Ewing in 1921 [1]. EWS of the bone, which most commonly occurs in children and young adults, accounts for approximately $3 \%$ of all pediatric cancers and most cases arise in the long bones or the pelvis [2]. Primary EWS of the head and neck region is extremely rare, accounting for only 49\% of all EWSs [3-6]. Furthermore, sinonasal lesions are uncommon. Only 14 cases of EWS involving the nasal cavity or the paranasal sinuses have been reported in the world's otolaryngology literature [7-9]. We herein present a case of EWS arising in the left ethmoid sinus.

\section{Case Report}

A 23-year-old male visited the otorhinolaryngology department for left purulent rhinorrhea and progressive nasal obstruction for 3 months. His past history was unremarkable. At the endoscopic examination, a large vascular polypoid mass was found to completely fill the left nasal cavity and the nasal septum was excluded to the right side (Fig. 1a, b). CT and MRI images showed a large hypervascular mass involving the left nasal airway, maxillary antrum, and anterior ethmoid cells. There was no bony erosion or contiguous spread, and the remaining sinuses, orbit, and cranial fossa were uninvolved (Fig. 2a, b). We embolized the mass (Fig. 3a) and subsequently performed surgical resection. Angiography of the left maxillary artery showed deep dyeing of the mass and gelatin was injected into the artery (Fig. 3b). A lateral rhinotomy approach was utilized to gain access to the tumor, followed by dissection along the medial wall of the orbit and around the tumor (Fig. 3c). A microscopic analysis revealed an undifferentiated tumor consisting of a solid sheet of small, round blue cells (Fig. 4a, b). Immunohistochemically, the tumor cells were strongly positive for CD99 (Fig. 4c). Molecular studies using PCR confirmed the chromosomal translocation of FLI1 (exon 6) (Fig. 5). These findings led to a diagnosis of EWS. Adjuvant chemotherapy consisting of vincristine, doxorubicin, and cyclophosphamide alternating with ifosfamide and etoposide (total: 7 cycles) was commenced. Radiation therapy was also administered for local control (total dose: 50.4 Gy) (Fig. 6). The patient has remained alive without evidence of recurrence or metastasis for $2 \frac{1}{2}$ years.

\section{Discussion}

EWS is a highly malignant, small, round cell tumor that originates from the primitive neuroectodermal cells. It was first described by James Ewing in 1921 [1]. Primary EWS commonly occurs in early childhood or adolescence and rarely occurs in adulthood. There is a slightly male predominance with a male-to-female ratio of 1.5:1 [7, 10,11]. Primary EWS of the head and neck region is extremely rare and accounts for only 4-9\% of all EWSs [3-6]. In general, approximately $20-30 \%$ of EWS patients present with metastases at the time of their diagnosis [12-16]. Patients with EWS of the head and neck region less frequently have metastases at diagnosis $[3,4,9,17-20]$. In our case, the patient did not have metastasis. Microscopically, these tumors are composed of uniform small round cells with round nuclei containing fine chromatin and scant clear or eosinophilic cytoplasm. In the sinonasal tract, the differential diagnosis includes all tumors that are composed of small round cells, such as 
olfactory neuroblastoma and undifferentiated carcinoma [21]. The diagnosis requires a histopathological examination, immunohistochemistry, and a cytogenetic analysis. The essential diagnostic examination to differentiate EWS from the many small round neoplasms is the CD99 marker, which can be detected in a specific immunohistochemical examination. In addition, molecular studies using PCR to detect the characteristics of chromosomal translocation are definitive for the diagnosis of EWS. A gene sequence, $t(11 ; 22)(q 24 ; q 12)$, which results in the fusion of the EWS gene with the FLI gene, is a specific genetic hallmark of EWS [22-24]. In our case, the patient was positive for the CD99 marker and the FLI gene. In general, the treatment of EWS consists of induction chemotherapy, followed by local control, which usually involves surgical resection, possibly followed by radiotherapy, and subsequent adjuvant chemotherapy. Aside from the patient characteristics, local control also affects outcome $[13,25]$. In EWS of the extremities, surgical resection (with or without radiotherapy) has been shown to be superior to radiotherapy alone [26]. Generally, EWS treatment begins with induction chemotherapy followed by local control. Adequate surgical removal with radical resection is desirable. Surgery should be combined with additional radiotherapy in cases involving a marginal resection and/or poor histological response. Local control is followed by adjuvant chemotherapy. In many cases, this approach is not practical for patients with EWS of the head and neck [27]. In our case, the patient was treated with postoperative combined chemotherapy and radiotherapy. Adjuvant chemotherapy was commenced. The patient also received radiation therapy for local control (total dose: 50.4 Gy). The patient remains alive without evidence of recurrence or metastasis at 3 years since the first examination.

\section{Statement of Ethics}

The authors have no ethical conflicts to disclose.

\section{Disclosure Statement}

The authors have no conflicts of interest to declare.

\section{References}

1 Ewing J: Diffuse endothelioma of bone. Pathol Soc 1921;21:17-24.

$\checkmark 2$ Ludwig JA: Ewing sarcoma: historical perspectives, current state-of-the-art, and opportunities for targeted therapy in the future. Curr Opin Oncol 2008;20:412-418.

3 Siegal GP, Oliver WR, Reinus WR, Gilula LA, Foulkes MA, Kissane JM, Askin FB: Primary Ewing's sarcoma involving the bones of head and neck. Cancer 1987;60:2829-2840.

-4 Allam A, El-Husseinty G, Khafaga Y, Kandil A, Gray A, Ezzat A, Schultz H: Ewing's sarcoma of the head and neck: a retrospective analysis of 24 cases. Sarcoma 1999;3:11-15.

-5 Carlotti CG Jr, Drake JM, Hladky JP, Teshima I, Becker LE, Rutka JT. Primary Ewing's sarcoma of the skull in children. Utility of moleculer diagnostics, surgery and adjuvant therapies. Pediatr Neurosurg 1999;31:307-315.

6 Desai KI, Nadkarni TD, Goel A, Muzumdar DP, Naresh KN, Nair CN: Primary Ewing's sarcoma of the cranium. Neurosurgery 2000;46:62-68.

-7 Yeshvanth SK, Ninan K, Bhandary SK, Lakshinarayana KP, Shetty JK, Makannavar JH: Rare case of extraskeletal Ewings sarcoma of the sinonasal tract. J Cancer Res Ther 2012;8:142-144.

8 Coskun BU, Cinar U, Savk H, Basak T, Dadas B: Isolated maxillary sinus Ewing's sarcoma. Rhinology 2005;43:225-228. 


\section{Case Reports in Oncology}

Gupta S, Gupta OP, Mehrotra S, Mehrotra D: Ewing sarcoma of the maxilla: a rare presentation. Quintessence Int 2009;40:135-140.

10 Howarth KL, Khodaei I, Karkanevatos A, Clarke RW. A sinonasal primary Ewing's sarcoma. Int J Pediatr Otorhinolaryngol 2004;68:221-224.

$>11$ Csokonai LV, Liktor B, Arató G, Helffrich F: Ewing's sarcoma in the nasal cavity. Otolaryngol Head Neck Surg 2001;125:665-667.

-12 Cotterill SJ, Ahrens S, Paulussen M, Jürgens HF, Voûte PA, Gadner H, Craft AW: Prognostic factors in Ewing's tumor of bone: analysis of 975 patients from the European Intergroup Cooperative Ewing's Sarcoma Study Group. J Clin Oncol 2000;18:3108-3114.

13 Bacci G, Longhi A, Ferrari S, Mercuri M, Versari M, Bertoni F: Prognostic factors in non-metastatic Ewing's sarcoma tumor of bone: an analysis of 579 patients treated at a single institution with adjuvant or neoadjuvant chemotherapy between 1972 and 1998. Acta Oncol 2006;45:469-475.

-14 Daw NC, Mahmoud HH, Meyer WH, Jenkins JJ, Kaste SC, Poquette CA, Kun LE, Pratt CB, Rao BN: Bone sarcomas of the head and neck in children: the St Jude Children's Research Hospital experience. Cancer 2000;88:2172-2180.

15 Esiashvili N, Goodman M, Marcus RB Jr: Changes in incidence and survival of Ewing sarcoma patients over the past 3 decades: Surveillance Epidemiology and End Results data. J Pediatr Hematol Oncol 2008;30:425-430.

-16 Krishnamani K, Kumar TN, Gandhi LV, Raghunadharao D, Sadashivudu G, Megha U: Pri- mary Ewing's sarcoma of the cranium: case series and review of literature. J Cancer Res Ther 2014;10:377-380.

17 Whaley JT, Indelicato DJ, Morris CG, Hinerman RW, Amdur RJ, Mendenhall WM, Keole SR, Marcus RB Jr: Ewing tumors of the head and neck. Am J Clin Oncol 2010;33:321-326.

18 Salunke PS, Gupta K, Malik V, Kumar N, Henke LE, Cai C, Chen WS, Pfeifer JD: Primary Ewing's sarcoma of cranial bones: analysis of ten patients. Acta Neurochir (Wien) 2011;153:1477-1485.

-19 Zöllner S, Dirksen U, Jürgens H, Ranft A: Renal Ewing tumors. Ann Oncol 2013;24:2455-2461.

-20 Jenkin RD, Al-Fawaz I, Al-Shabanah MO, Allam A, Ayas M, Memon M, Rifai S, Schultz HP: Metastatic Ewing sarcoma/PNET of bone at diagnosis: prognostic factors - a report from Saudi Arabia. Med Pediatr Oncol 2001;37:383-389.

-21 Yeshvanth SK, Ninan K, Bhandary SK, Lakshinarayana KP, Shetty JK, Makannavar JH: Rare case of extraskeletal Ewings sarcoma of the sinonasal tract. J Cancer Res Ther 2012;8:142-144.

-22 Kawabata M, Yoshifuku K, Sagara Y, Kurono Y: Ewing's sarcoma/primitive neuroectodermal tumour occurring in the maxillary sinus. Rhinology 2008;46:75-78.

23 Gupta S, Gupta OP, Mehrotra S, Mehrotra D: Ewing sarcoma of the maxilla: a rare presentation Quintessence Int 2009;40:135-140.

24 Iezzoni JC, Mills SE: "Undifferentiated" small round cell tumors of the sinonasal tract: differential diagnosis update. Am J Clin Pathol 2005;124(suppl):S110-S121.

25 Haeusler J, Ranft A, Boelling T, Gosheger G, Braun-Munzinger G, Vieth V, Burdach S, van den Berg H, Juergens H, Dirksen U: The value of local treatment in patients with primary, disseminated, multifocal Ewing sarcoma (PDMES). Cancer 2010;116:443-450.

-26 Schuck A, Ahrens S, Paulussen M, Kuhlen M, Könemann S, Rübe C, Winkelmann W, Kotz R, Dunst J, Willich N, Jürgens H: Local therapy in localized Ewing tumors: results of 1,058 patients treated in the CESS 81, CESS 86, and EICESS 92 trials. Int J Radiat Oncol Biol Phys 2003;55:168-177.

27 Grevener K, Haveman LM, Ranft A, van den Berg H, Jung S, Ladenstein R, Klco-Brosius S, Juergens H, Merks JH, Dirksen U: Management and outcome of Ewing sarcoma of the head and neck. Pediatr Blood Cancer 2016;63:604-610. 


\section{Case Reports in Oncology}

\begin{tabular}{|c|c|}
\hline \multicolumn{2}{|c|}{ Case Rep Oncol 2017;10:91-97 } \\
\hline DOI: $10.1159 / 000455040$ & $\begin{array}{l}\text { (C) } 2017 \text { The Author(s). Published by S. Karger AG, Basel } \\
\text { www.karger.com/cro }\end{array}$ \\
\hline
\end{tabular}
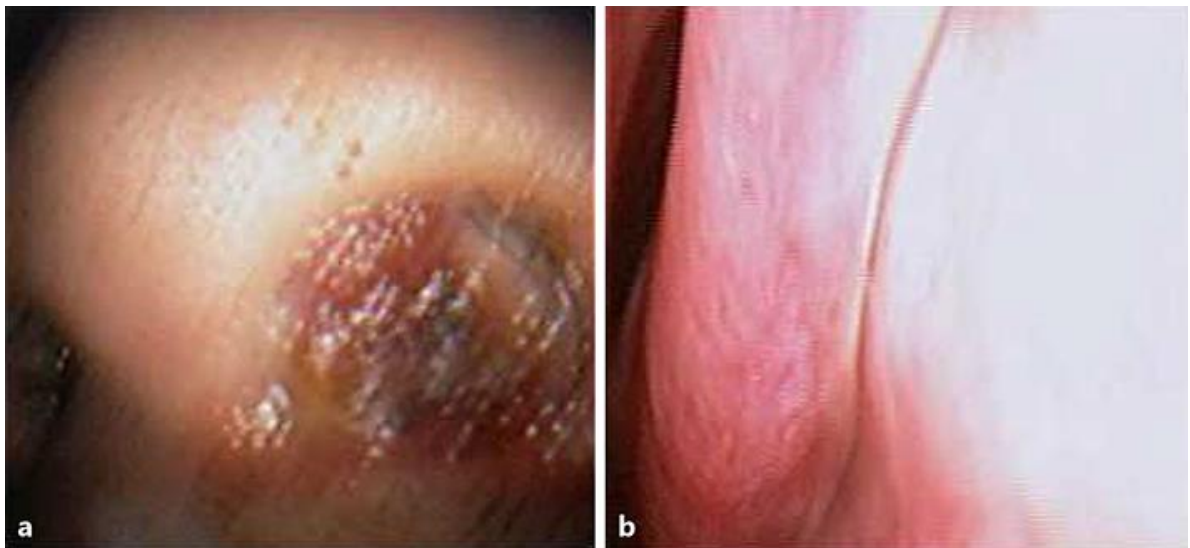

Fig. 1. a A large vascular polypoid mass completely filling the left nasal cavity. $\mathbf{b}$ The nasal septum is excluded to the right side.
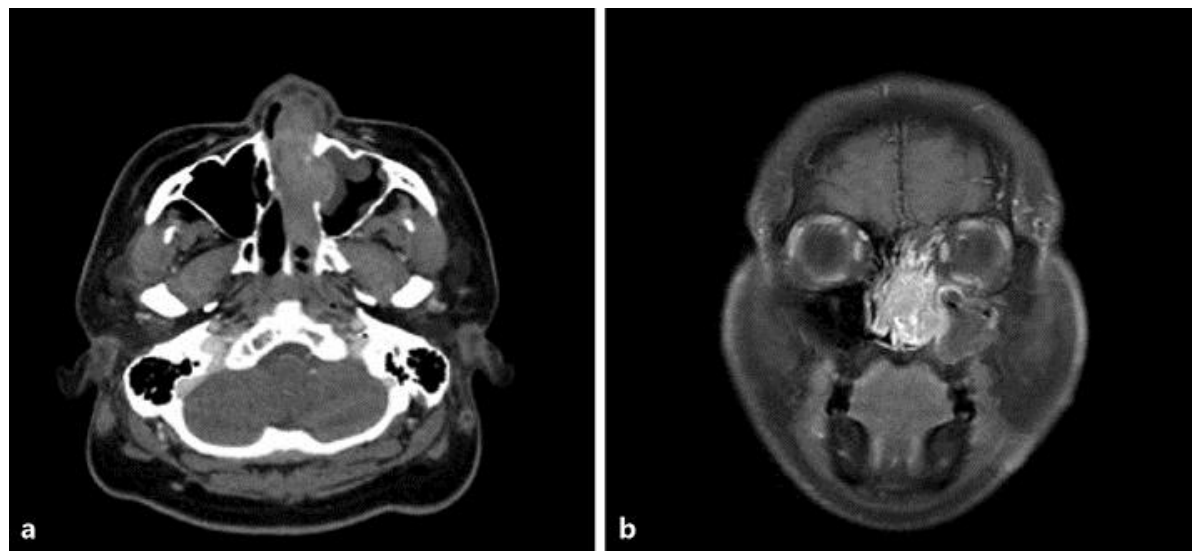

Fig. 2. a, b CT and MRI (T1) showed a large hypervascular mass involving the left nasal airway, maxillary antrum, and anterior ethmoid cells. There was no bony erosion or contiguous spread, and the remaining sinuses, orbit, and cranial fossa were uninvolved.
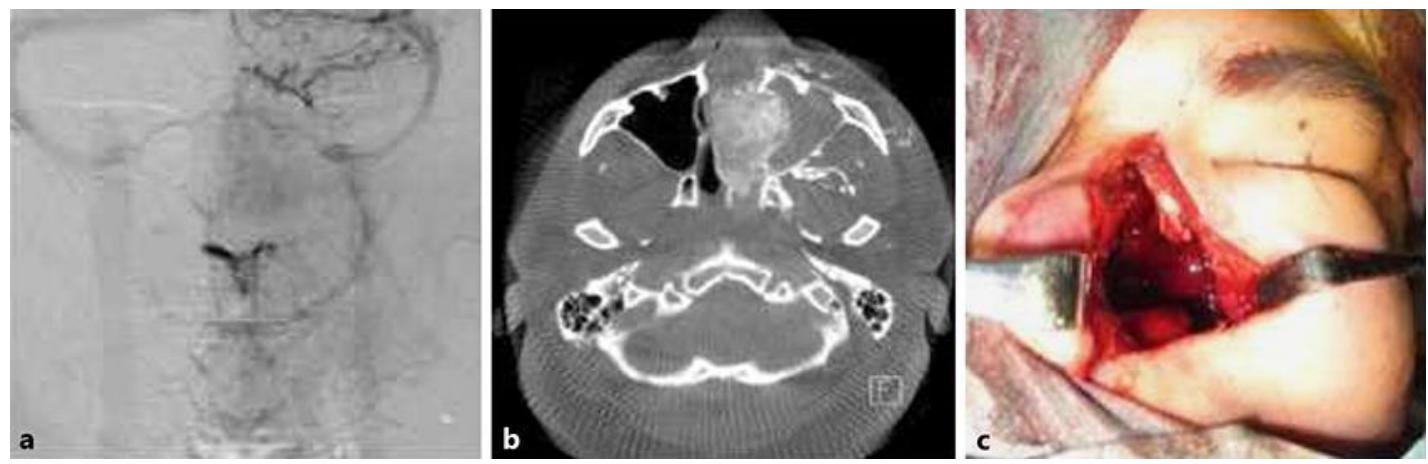

Fig. 3. a Angiography of left maxillary artery. b Gelatin was injected into the left maxillary artery. c A lateral rhinotomy approach was performed to remove the tumor. 


\section{Case Reports in Oncology}

\begin{tabular}{|c|c|}
\hline \multicolumn{2}{|c|}{ Case Rep Oncol 2017;10:91-97 } \\
\hline DOI: $10.1159 / 000455040$ & $\begin{array}{l}\text { (c) } 2017 \text { The Author(s). Published by S. Karger AG, Basel } \\
\text { www.karger.com/cro }\end{array}$ \\
\hline
\end{tabular}

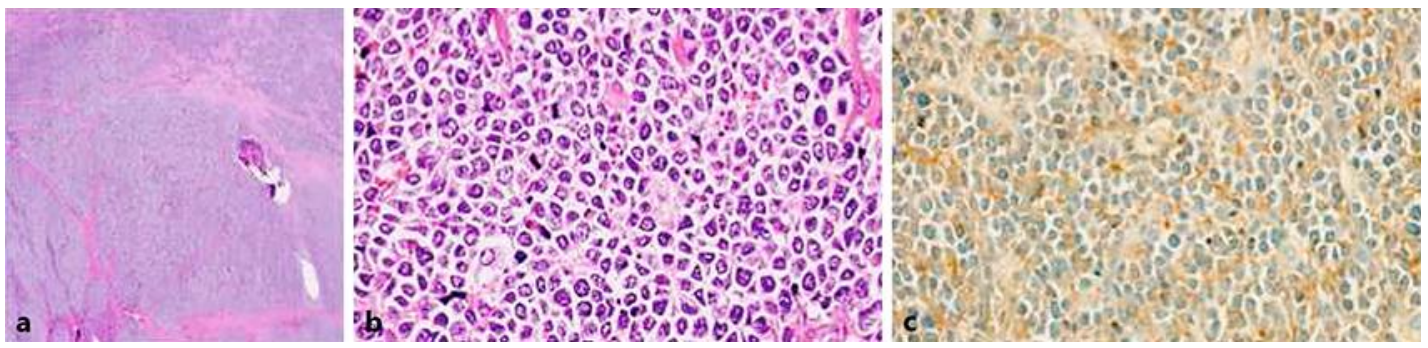

Fig. 4. Microscopic analysis revealed an undifferentiated tumor consisting of a solid sheet of small, round blue cells $(\mathbf{a} 10 \times 2$, b $10 \times 40)$. c Immunohistochemically, tumor cells showed strongly positive staining with CD99.

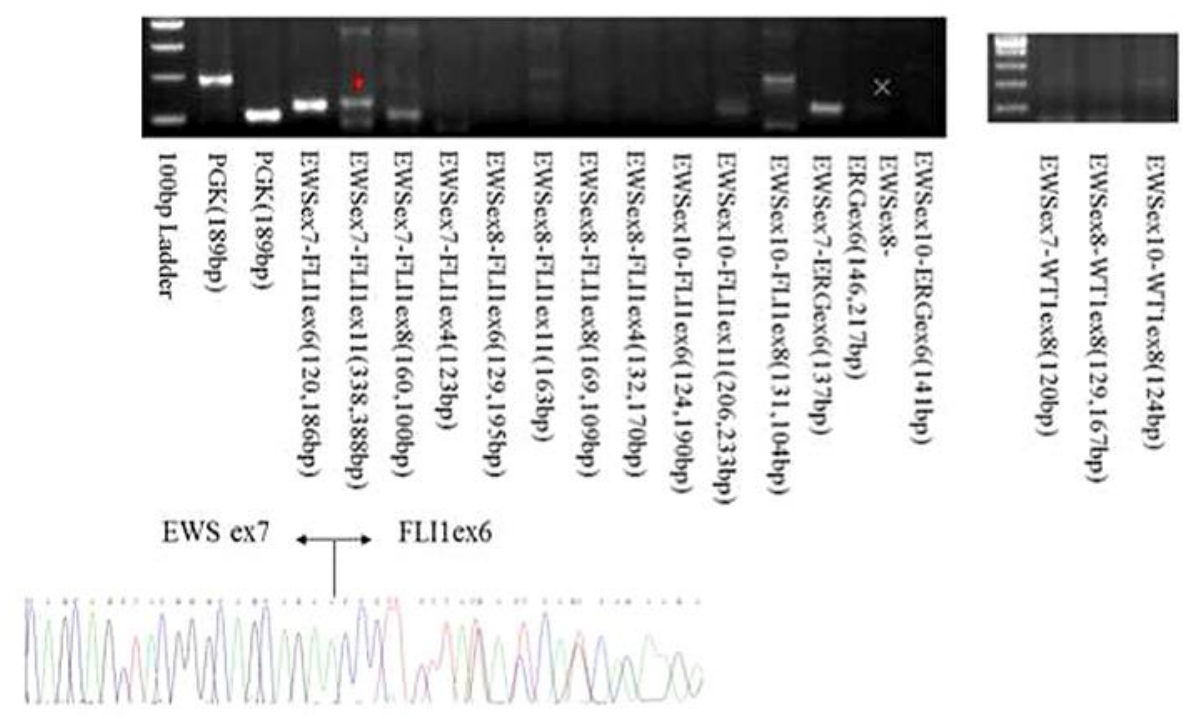

Fig. 5. Molecular studies using PCR analysis confirmed the chromosomal translocation of FLI1 (exon 6). 

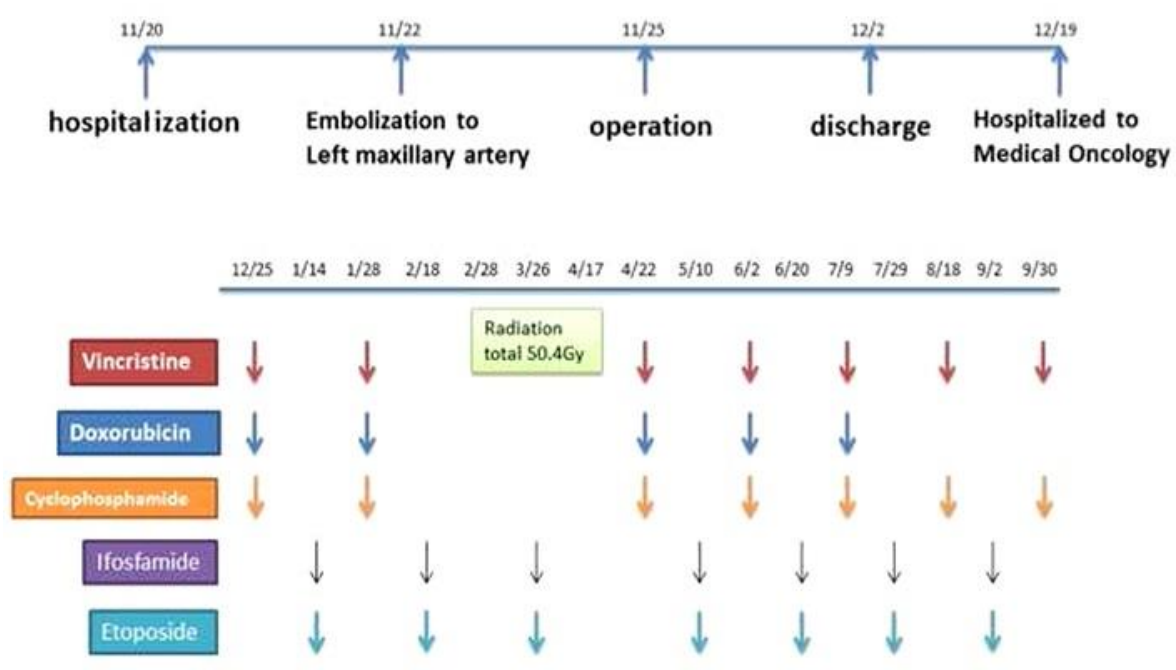

Fig. 6. Adjuvant chemotherapy consisting of vincristine, doxorubicin, and cyclophosphamide alternating with ifosfamide and etoposide (7 cycles total) was commenced. He also received radiation therapy for local control (total dose of $50.4 \mathrm{~Gy}$ ). The patient is alive without evidence of recurrence or metastasis. 